\title{
Diversity Analysis of Sweet Potato Genetic Resources Using Morphological and Qualitative Traits and Molecular Markers
}

\author{
Fabio Palumbo, Aline Carolina Galvao, Carlo Nicoletto * $\mathbb{D}^{\mathbb{D}}$, Paolo Sambo ${ }^{\mathbb{D}}$ and \\ Gianni Barcaccia $\mathbb{D}$ \\ Department of Agronomy, Food, Natural resources, Animals and Environment (DAFNAE) University of \\ Padova, Agripolis Campus, Viale dell'Università, 16-35020 Legnaro, Italy; fabio.palumbo@unipd.it (F.P.); \\ aline.galvao@unipd.it (A.C.G.); paolo.sambo@unipd.it (P.S.); gianni.barcaccia@unipd.it (G.B.) \\ * Correspondence: carlo.nicoletto@unipd.it; Tel.: +39-049-827-2826
}

Received: 24 September 2019; Accepted: 22 October 2019; Published: 24 October 2019

\begin{abstract}
The European Union (EU) market for sweet potatoes has increased by $100 \%$ over the last five years, and sweet potato cultivation in southern European countries is a new opportunity for the EU to exploit and introduce new genotypes. In view of this demand, the origins of the principal Italian sweet potato clones, compared with a core collection of genotypes from Central and Southern America, were investigated for the first time. This was accomplished by combining a genetic analysis, exploiting 14 hypervariable microsatellite markers, with morphological and chemical measurements based on 16 parameters. From the molecular analyses, Italian accessions were determined to be genetically very similar to the South American germplasm, but they were sub-clustered into two groups. This finding was subsequently confirmed by the morphological and chemical measurements. Moreover, the analysis of the genetic structure of the population suggested that one of the two groups of Italian genotypes may have descended from one of the South American accessions, as predicted on the basis of the shared morphological characteristics and molecular fingerprints. Overall, the combination of two different characterization methods, genetic markers and agronomic traits, was effective in differentiating or clustering the sweet potato genotypes, in agreement with their geographical origin or phenotypic descriptors. This information could be exploited by both breeders and farmers to detect and protect commercial varieties, and hence for traceability purposes.
\end{abstract}

Keywords: Ipomoea batatas; genetic diversity; SSR markers; qualitative traits

\section{Introduction}

Sweet potato (Ipomoea batatas Lam.) is a root crop of the Convolvulaceae family, originating in Central and South America, which spread through the world with great ease due to its prominent productive efficiency. This crop plays a vital role in food production because it is one of the most important root and tuber crops in the world. Its ability to produce energy is very efficient and it can provide a significant quantity of protein and sugars per hectare in a short time [1].

In the European context, this crop had an enormous rise in consumption and, according to the Center for the Promotion of Imports from Developing Countries (CBI) [2], its importation has doubled in recent years. The European Union (EU) market for sweet potatoes has increased by $100 \%$ over the last five years (CBI, 2015), and sweet potato cultivation in southern European countries presents a new opportunity for the EU to exploit and introduce new genotypes. In Italy, it is considered a niche and ethnic product, and the recent immigration flow has created a market with increasing domestic demand [3] and many future opportunities for growth and profitability. 
Despite the historical and commercial importance of sweet potatoes, to date, no study has investigated the origin, the conservation, or the genetic background of this species in Italy. On a larger scale, several works have been published [4-8] on the genetic characterization of sweet potato accessions, mainly to investigate the dispersal of New World sweet potato landraces from the center of origin (Tropical America, [9]). One of the main obstacles to the understanding of the dispersal dynamics of sweet potato throughout the world is probably the genetics of this hexaploid species $(2 n=6 \mathrm{x}=90)$ [10], which severely complicates any genomic approach. In particular, sweet potato is an allohexaploid species (AABBBB), most likely derived from the interspecific hybridization between a diploid and tetraploid species followed by chromosomal doubling [11,12]. As a consequence, its inheritance model is admixed, including both disomic (AA) and tetrasomic (BBBB) pairings. On the other hand, it must be recognized that this polyploidy could represent an important source of genetic diversity [13]. According to Silva Ritschel and Huamán [14], the vast genetic diversity that characterizes the sweet potato germplasm is also due to sexual reproduction (i.e., genetic segregation and recombination) and asexual propagation (i.e., fixation of specific genetic combinations), as well as to the exchange and introduction of plants from all over the world. This diversity provides a valuable source for potentially useful traits and allows plant breeders and farmers to adapt the crop to heterogeneous and changing environments [15]. The evolving climate conditions and the staggering expansion of the world population together represent pressing challenges for agriculture.

As already seen in other crops, morphological, agronomic, and molecular marker approaches are often used in combination to complement the information provided singularly in order to investigate the heterogeneity described in a species [16]. Molecular markers such as microsatellites or SSRs play a central role in the assessment and conservation of genetic diversity due to their efficiency, reliability, and reproducibility. Several studies based on the application of SSRs have recently attempted to monitor and prevent genetic erosion of local crop varieties in Italian scenarios [15,17-19]. Estimating the allelic dosage at each locus represents a critical question in polyploid species, even when using co-dominant markers such as microsatellites [20]. For this reason, as has already been done in previous studies [21-23], SSRs were scored as dominant markers and organized in binary matrixes, similarly to the process with AFLP or RAPD markers. According to Silva Ritschel and Huamán [14], morphological and chemical characterization is an indirect measure of population genetic diversity. Morphological markers for sweet potatoes are accessible and easy to use, making the technique one of the most used for this kind of analysis [24-26].

In this study, the geographical and genetic origins of the principal Italian sweet potato accessions were compared with a core collection of accessions from Central and South America for the first time. As has already been achieved in previous works on sweet potato $[27,28]$, this was achieved by combining the high polymorphism and reproducibility of SSR markers with the high information value of strategic morphological and qualitative traits.

\section{Materials and Methods}

\subsection{Plant Material}

The cultivation was carried out at the experimental farm "L. Toniolo" of Padova University $\left(45^{\circ} 21^{\prime} \mathrm{N} ; 11^{\circ} 58^{\prime} \mathrm{E} ; 8 \mathrm{~m}\right.$ a.s.l.) in the 2016 spring/fall growing cycle. The propagation material used in the experiment was obtained from the germplasm bank of the Padova University (Table 1). The pedigree information of the plant materials derived from Central and Sothern America is unknown; as to the origin of Italian genotypes, we only know that they were introduced into Tuscany in 1630, cultivated until the end of the 1800s exclusively in botanical gardens, and only spread to the Northern Italy cultivation areas from 1880. In January 2016, sweet potato cuttings were produced in a glass greenhouse set with a temperature of $25^{\circ} \mathrm{C}$ and $18{ }^{\circ} \mathrm{C}$ during the day and night, respectively. Thirty storage roots for each genotype, $40 \mathrm{~mm}$ to $80 \mathrm{~mm}$ in diameter, were placed in PVC pots (three roots per pot) filled with a peaty substrate (Klasmann Potgrond $\mathrm{H}$ ) integrated with $20 \%$ perlite. In May, the cuttings were 
suitable for transplanting (0.30-0.35 $\mathrm{m}$ tall). Before transplanting, the soil was plowed and fertilized with 80,70 , and $210 \mathrm{~kg}^{-1}$ of $\mathrm{N}, \mathrm{P}_{2} \mathrm{O}_{5}$, and $\mathrm{K}_{2} \mathrm{O}$, respectively [29]. Cuttings were planted $0.10 \mathrm{~m}$ deep on the built-up rows, spacing the plants $0.35 \mathrm{~m}$ apart in the row and $0.80 \mathrm{~m}$ between rows. After transplanting, approximately $100 \mathrm{~mL}$ of water was provided for each cutting. The crop was irrigated three times during the growing cycle, at a rate of $30 \mathrm{~mm} \mathrm{~m}^{-2}$ for each irrigation. Sweet potatoes were harvested at the end of September 2016.

Table 1. List of sweet potato genotypes used.

\begin{tabular}{|c|c|c|c|c|c|}
\hline $\begin{array}{l}\text { Genetic } \\
\text { Material }\end{array}$ & Plant Type & $\begin{array}{c}\text { Country of } \\
\text { Origin }\end{array}$ & Flesh Color & Skin Color & Root Shape \\
\hline BR_1 & Extremely spreading & Brazil & Purple & Dark purple & Elliptical \\
\hline BR_13 & Extremely spreading & Brazil & White & Cream & Elliptical \\
\hline BR_25 & Semi-erect & Brazil & Purple & Cream & Long oblong \\
\hline BR_30 & Spreading & Brazil & White & Pink & Long irregular \\
\hline BR_33 & Semi-erect & Brazil & Purple & Cream & Oblong \\
\hline BR_51 & Extremely spreading & Brazil & White & Cream & Long elliptical \\
\hline BR_53 & n.a. & Brazil & Purple & White & Oblong \\
\hline BR_54 & Extremely spreading & Brazil & Intermediate orange & Yellow & Elliptical \\
\hline BR_66 & n.a. & Brazil & White & White & Irregular \\
\hline IT_43 & Spreading & Italy & Pale yellow & Pink & Obovate \\
\hline IT_44 & Semi-erect & Italy & White & Cream & Elliptical \\
\hline IT_49 & Semi-erect & Italy & Pale yellow & Pink & Round elliptical \\
\hline alIT_81 & Erect & Italy & Cream & Cream & Obovate \\
\hline US_45 & Semi-erect & USA & Purple & Dark purple & Long oblong \\
\hline US_85 & n.a. & USA & Pale yellow & Cream & Round elliptical \\
\hline HO_86 & n.a. & Honduras & Deep Orange & Purple red & Round elliptical \\
\hline
\end{tabular}

n.a.: not available.

\subsection{Molecular Analysis}

\subsubsection{Genomic DNA Isolation}

Leaves were collected from 1 month old transplants, snap-frozen in liquid nitrogen upon harvesting, and stored at $-20^{\circ} \mathrm{C}$ until further processing. Approximately $100 \mathrm{mg}$ of leaf tissue was employed for the isolation of genomic DNA using the DNeasy plant kit (Qiagen, Valencia, CA, USA), according to the manufacturer's instructions. Extracted DNA samples were run on $0.8 \%$ agarose/1× TAE gel containing 1×SYBR Safe DNA stain (Life Technologies, Carlsbad, CA, USA) to evaluate their integrity. Both the purity and quantity were assessed with a NanoDrop 2000c UV-Vis spectrophotometer (Thermo Scientific, Pitsburgh, PA, USA).

\subsubsection{SSR Genotyping}

For the SSR analysis, microsatellite markers belonging to 14 distinct genomic loci from both coding regions (EST-SSR) and non-coding regions (nSSR) were obtained from different sources $[4,5,10,30]$ (Table 2). These markers were chosen due to the high polymorphism they showed in the reference studies. In order to evaluate the efficiency and the polymorphism degree of this SSR set, a preliminary test was performed using three different clones randomly chosen from the sweet potato collection, and each was analyzed in two biological replicates (i.e., two distinct plants for each clone). Moreover, each biological replicate was, in turn, analyzed in two technical replicates, to evaluate the reproducibility of the SSR. 
Table 2. List of SSR marker loci used in this study along with their basic information. For each SSR region, locus name, melting temperature (Tm), primer sequences, microsatellite motif, number of alleles according to the reference study, amplicon length in base pairs (bp), microsatellite type (including $n$ SSR $=$ SSR from non-coding regions and EST-SSR = SSR from coding regions), multiplex organization (for the simultaneous run of PCR products from different SSR marker loci in capillary electrophoresis) and the sources from which the SSR data were obtained are reported. Colored bases at the 5' end of each forward primer represent four universal sequences (designated as M13, in blue, PAN1, in green, PAN2, in yellow and PAN3, in red) complementary to as many fluorophore-labeled oligonucleotides (fluorophores adopted were 6-FAM, VIC, NED and PET).

\begin{tabular}{|c|c|c|c|c|c|c|c|c|}
\hline Locus Name & $\operatorname{Tm}\left({ }^{\circ} \mathrm{C}\right) *$ & Primer Sequence $\left(5^{\prime}-3^{\prime}\right)$ & SSR Motif & Alleles & Length (bp) & Type & Multiple $\times$ & Source \\
\hline IBSSR04 & $\begin{array}{l}62 \\
62\end{array}$ & $\begin{array}{c}\text { GAGGTAGTTATTGTGGAGGACCTCCTTTGCCTCCTTTCATGC } \\
\text { CСTTGCTCCCCATTTTCTTCTTG }\end{array}$ & (GA)11 & 7 & 216 & nSSR & 1 & {$[30]$} \\
\hline $\mathrm{J} 263$ & $\begin{array}{l}62 \\
61\end{array}$ & $\begin{array}{l}\text { GGAATTAACCGCTCACTAAAGCTCTGCTTCTCCTGCTGCTT } \\
\text { GTGCGGCACTTGTCTTTGATA }\end{array}$ & $(\mathrm{AAC}) 6$ & 7 & $156-171$ & nSSR & 1 & [5] \\
\hline $\mathrm{J} 544 \mathrm{~b}$ & $\begin{array}{l}61 \\
59\end{array}$ & $\begin{array}{l}\text { TTGTAAAACGACGGCCAGTAGCAGTTGAGGAAAGCAAGG } \\
\text { CAGGATTTACAGCCCCAGAA }\end{array}$ & (TCT)6 & 8 & 174-194 & nSSR & 1 & [5] \\
\hline Ib318 & $\begin{array}{l}60 \\
60\end{array}$ & $\begin{array}{l}\text { GAGGTAGTTATTGTGGAGGACAGAACGCATGGGCATTGA } \\
\text { CCCACCGTGTAAGGAAATCA }\end{array}$ & n.a. & 5 & $125-135$ & nSSR & 1 & [4] \\
\hline $\mathrm{Ib}-255 \mathrm{~F} 1$ & $\begin{array}{l}61 \\
59\end{array}$ & $\begin{array}{l}\text { GGAATTAACCGCTCACTAAAGCGTCCATGCTAAAGGTGTCAA } \\
\text { ATAGGGGATTGTGCGTAATTTG }\end{array}$ & n.a. & 8 & $210-245$ & nSSR & 2 & [4] \\
\hline $\mathrm{Ib} 297$ & $\begin{array}{l}59 \\
60\end{array}$ & $\begin{array}{l}\text { GAGGTAGTTATTGTGGAGGACGCAATTTCACACACAAACACG } \\
\text { CCCTTCTTCCACCACTTTCA }\end{array}$ & (CT)13 & 24 & $129-167$ & nSSR & 2 & [5] \\
\hline $\mathrm{Ib} 286$ & $\begin{array}{l}62 \\
57\end{array}$ & $\begin{array}{c}\text { TTGTAAAACGACGGCCAGTAGCCACTCCAACAGCACATA } \\
\text { GGTTTCCCAATCAGCAATTC }\end{array}$ & n.a. & 10 & $90-122$ & nSSR & 2 & {$[4]$} \\
\hline $\mathrm{IbS} 11$ & $\begin{array}{l}58 \\
61\end{array}$ & $\begin{array}{l}\text { GGAATTAACCGCTCACTAAAGCCCTGCGAAATCGAAATCT } \\
\text { GGACTTCCTCTGCCTTGTTG }\end{array}$ & (TTC)10 & 13 & $218-248$ & nSSR & 3 & [5] \\
\hline J116a & $\begin{array}{l}57 \\
60\end{array}$ & $\begin{array}{l}\text { GAGGTAGTTATTGTGGAGGACTCTTTTGCATCAAAGAAATCCA } \\
\text { CCTCAGCTTCTGGGAAACAG }\end{array}$ & $(\mathrm{CCT}) 7$ & 15 & $187-227$ & nSSR & 3 & {$[5]$} \\
\hline $\mathrm{J} 206 \mathrm{~A}$ & $\begin{array}{l}59 \\
57\end{array}$ & $\begin{array}{c}\text { TTGTAAAACGACGGCCAGTATCAGGGAGAGAGGACAGTAA } \\
\text { TAGGCAAACCATAAACAGAGA }\end{array}$ & $(\mathrm{GAT}) 6$ & 9 & $103-121$ & nSSR & 3 & [5] \\
\hline GDAAS0615 & $\begin{array}{l}56 \\
57\end{array}$ & $\begin{array}{l}\text { TGTAGAAAGACGAAGGGAAGGCCACATACAGACTACAACTTAC } \\
\text { GGAGGAGCGTATTATGAACA }\end{array}$ & (GA)10 & 7 & 230 & EST-SSR & 4 & [10] \\
\hline GDAAS0757 & $\begin{array}{l}56 \\
56\end{array}$ & $\begin{array}{c}\text { TTGTAAAACGACGGCCAGTGAGATGATGACGATAGTGTTG } \\
\text { GGAAGATTCATTGGCAGAAG }\end{array}$ & (GAA)11 & 9 & 293 & EST-SSR & 4 & [10] \\
\hline IBSSR27 & $\begin{array}{l}56 \\
55\end{array}$ & $\begin{array}{l}\text { GGAATTAACCGCTCACTAAAGGTGTTTATCACATCGTTTTCTG } \\
\text { GGCTCGTACAATTTTCAAAG }\end{array}$ & (TA)6(CA)16 & 9 & 149 & nSSR & 4 & [30] \\
\hline GDAAS0156 & $\begin{array}{l}54 \\
55\end{array}$ & $\begin{array}{c}\text { GAGGTAGTTATTGTGGAGGACTCCAAATACCATACCCAAC } \\
\text { CGCTTTCAAATAGAATCGTC }\end{array}$ & (TC)10 & 8 & 118 & EST-SSR & 4 & [10] \\
\hline
\end{tabular}

${ }^{*}$ Tm of the forward primers does not take into account the tail sequence. 
The PCRs were carried out via the three-primer strategy reported by Schuelke [31], with a major modification first described by Palumbo et al. [32]; Instead of using only M13, three additional universal sequences (designated as PAN1, PAN2, and PAN3) were used to tag the $5^{\prime}$ end of the forward primer of each couple (colored sequences in Table 2) and adopted in combination with M13, PAN1, PAN2, and PAN3 fluorophore-labeled oligonucleotides. Fluorophores adopted were 6-FAM, VIC, NED, and PET, respectively. Due to the genetic complexity of the species and thus the possibility of obtaining up to six alleles per SSR locus, PCRs were performed in single reactions. Each reaction contained approximately $40 \mathrm{ng}$ of genomic DNA template, $1 \times$ Platinum ${ }^{\circledR}$ Multiplex PCR Master Mix (Applied Biosystems, Carlsbad, CA, USA), GC enhancer 10\% (Applied Biosystems), $0.05 \mu \mathrm{M}$ tailed forward primer (Invitrogen Corporation, Carlsbad, CA, USA), $0.1 \mu \mathrm{M}$ reverse primer (Invitrogen Corporation), $0.23 \mu \mathrm{M}$ universal primer (Invitrogen Corporation), and sterile water to volume. Amplifications were performed in a 96 well plate using a 9600 thermal cycler (Applied Biosystems), adopting the following conditions: after initial denaturation for $2 \mathrm{~min}$ at $95^{\circ} \mathrm{C}$, a touch-down PCR was undertaken with six cycles consisting of $30 \mathrm{~s}$ denaturation at $95{ }^{\circ} \mathrm{C}, 1 \mathrm{~min}$ annealing at $60{ }^{\circ} \mathrm{C}$ decreasing by $1.0^{\circ} \mathrm{C}$ with each cycle and $30 \mathrm{~s}$ elongation at $72{ }^{\circ} \mathrm{C}$; then 35 cycles at $95^{\circ} \mathrm{C}$ for $30 \mathrm{~s}, 55^{\circ} \mathrm{C}$ for $60 \mathrm{~s}$, and $72{ }^{\circ} \mathrm{C}$ for $30 \mathrm{~s}$. A final extension at $60^{\circ} \mathrm{C}$ for $30 \mathrm{~min}$ terminated the reaction and filled in any protruding ends of the newly synthesized strands. The amplicons were visualized and quantified by agarose gel electrophoresis ( $2 \%$ agarose/ $1 \times$ TAE gel containing $1 \times$ Sybr Safe DNA stain (Life Technologies)), and the gel pictures were acquired with an UVITEC UV Transilluminator (Cambridge, UK) equipped with a digital camera. Subsequently, $10 \mathrm{ng}$ of each PCR product was pooled and organized according to the four multiplexes reported in Table 2 and subjected to capillary electrophoresis on an ABI PRISM 3130x1 Genetic Analyzer (Thermo Fisher) using LIZ500 (Applied Biosystems) as molecular weight standard and G5 (Applied Biosystems) as filter. Peak Scanner software v. 2.0 (Applied Biosystems) was used to determine the size of each peak, and each SSR was handled as a dominant marker. From the total of 14 SSR primer pairs initially selected for sweet potato genome analysis and tested for polymorphisms, Ib318 [4], J263 [5], and GDAAS0156 [10] showed weak resolution or screening errors and were excluded from our study.

\subsubsection{Marker Data Analysis}

Data were coded as $(0,1)$ vectors, where 1 indicated the presence and 0 the absence of a peak/allele at a specific position in the electropherogram. The polymorphic information content (PIC) of each SSR locus over its $n$ marker alleles was computed as [33],

$$
\mathrm{PIC}=1-\sum \mathrm{p}_{i}{ }^{2}
$$

where $\mathrm{p}_{i}$ is the frequency of the marker allele $i$.

Genetic similarity between the clones was estimated by applying Dice's coefficient [34] in all possible pairwise comparisons, and a triangular similarity data matrix was generated. The first two principal components of the matrix were thus computed through a principal coordinate analysis (PCoA). All calculations were conducted using NTSYS-pc v. 2.21q software [35]. Taking advantage of the genetic similarity data, PAST software v. 3.14 [36] was used to construct a dendrogram through the unweighted pair group arithmetic average (UPGMA) method and by applying the Dice's coefficient [34]. To measure the stability of the computed branches, a statistical bootstrap analysis was conducted with 1000 resampling replicates. GenAlEX software v. 6.5 [37] estimated the number of observed alleles and the presence of private allele throughput in all the samples, purposely grouped as "Italian clones $(N=5)^{\prime \prime}$ and "foreign clones $(N=17)$ " according to their putative origin. Marker alleles were scored as "private" when shared by at least $60 \%$ of the individuals of one group and simultaneously absent from the other group.

A Bayesian clustering algorithm implemented in STRUCTURE v. 2.2 software [38] was used to model the genetic structure of the considered I. batatas accessions' haploid genotypes. The "admixture 
model" and "correlated allele frequencies model" were selected, because no prior knowledge about their origin was available (first model) and to guarantee the identification of a previously undetected correlation without affecting the results if no correlation existed [39] (second model). The number of founding groups ranged from 2 to 10, and 10 replicate simulations were performed for each K value, setting a burn-in of $2 \times 10^{5}$ and a final run of $10^{6}$ Markov chain Monte Carlo (MCMC) steps [40]. Finally, the most likely estimation of $\mathrm{K}$ was decided by evaluating the rate of change in the log probability of data between successive $\mathrm{K}$ values ( $\Delta \mathrm{K}$ method), according to Evanno et al. [41]. In particular, one $2 \mathrm{D}$ Excel vertical histogram for each accession, conveniently divided into K colored segments, was used to represent the estimated membership in each hypothesized ancestral genotype. Each color correlated to a putative ancestor.

\subsection{Morphological and Chemical Analyses}

The morphological characterization was performed in August 2016. Root shape, root skin color, root flesh color, and the general outline of the leaf were scored according to the morphological descriptors available from International Board for Plant Genetic Resources (IBPGR) [42]. All the morphological traits considered for each genotype were transformed into numbers using the CIP scale [42] in order to process them with statistics. Three biological replicates were performed for the chemical analyses in order to recover representative data about the sweet potato samples.

\subsubsection{Extraction of Phenols for Analysis}

Freeze-dried samples (1 g) were extracted in methanol $(20 \mathrm{~mL})$ with an Ultra Turrax T25 (IKA-Labortechnik, Staufen, Germany) at $1018 \mathrm{rpm}$ until a uniform consistency was achieved. Samples were filtered (589 filter paper; Whatman, Germany) and appropriate aliquots of extracts were assayed by the Folin-Ciocalteu (FC) method [43] for total phenolic (TP) content, and by the ferric reducing antioxidant power (FRAP method) for antioxidant activity [44]. For HPLC analyses, extracts were further filtered with cellulose acetate syringe filters $(0.45 \mu \mathrm{m}$ porosity).

\subsubsection{Determination of TP Content by the FC Assay}

The TP content was determined according to the FC assay, using gallic acid as a calibration standard and a UV-1800 spectrophotometer (Shimadzu, Columbia, MD, USA). The FC assay was carried out by putting $200 \mu \mathrm{L}$ of sweet potato extract into a $10 \mathrm{~mL}$ test tube, followed by the addition of FC reagent $(1 \mathrm{~mL})$. The mixture was vortexed for $20-30 \mathrm{~s}$ and $800 \mu \mathrm{L}$ of filtered $20 \%$ sodium carbonate solution was added 1-8 min after the FC reagent addition. The mixture was then vortexed for 20-30 s (time 0 ). The absorbance of the colored reaction product was measured at $765 \mathrm{~nm}$ after two hours at room temperature. The TP content in the extracts was calculated from a standard calibration curve obtained with different concentrations of gallic acid, ranging from 0 to $600 \mu \mathrm{g} \mathrm{mL}{ }^{-1}$ (coefficient of determination: $\left.r^{2}=0.9992\right)$. The results have been expressed as mg gallic acid equivalent $\left(\mathrm{GAE}^{2} \mathrm{~kg}^{-1}\right.$ dry weight.

\subsubsection{Determination of Total Antioxidant Activity by FRAP}

Freshly prepared FRAP reagent contained $1 \mathrm{mmol} \mathrm{L}^{-1}$ 2,4,6-tripyridyl-2-triazine and $2 \mathrm{mmol} \mathrm{L}^{-1}$ ferric chloride in $0.25 \mathrm{~mol} \mathrm{~L}^{-1}$ sodium acetate $(\mathrm{pH} 3.6)$. A methanol extract aliquot $(100 \mu \mathrm{L})$ was added to the FRAP reagent $(1900 \mu \mathrm{L})$ and accurately mixed. Absorbance was determined at $593 \mathrm{~nm}$ after leaving the mixture at $20^{\circ} \mathrm{C}$ for $4 \mathrm{~min}$. The calibration was performed with a standard curve (0-1200 $\mu \mathrm{g} \mathrm{mL}^{-1}$ ferrous ion) (coefficient of determination: $\left.r^{2}=0.9985\right)$ obtained by the addition of freshly prepared ammonium ferrous sulfate. FRAP values were calculated as $\mu \mathrm{g} \mathrm{mL}{ }^{-1}$ ferrous ion (ferric reducing power) from three determinations and have been reported as $\mathrm{mg} \mathrm{kg}^{-1}$ of Fe $^{2+}$ (ferrous ion equivalent) of dry matter. 


\subsubsection{Quantitative Determination of Ions by IC and Organic Nitrogen}

For the estimation of anions and cations, a freeze-dried sample (200 $\mathrm{mg})$ was extracted in water $(50 \mathrm{~mL})$ and shaken at $150 \mathrm{rpm}$ for $20 \mathrm{~min}$. Samples were filtered in sequence through filter paper (589 Schleicher), and the extracts were further filtered through cellulose acetate syringe filters $(0.20 \mathrm{~mm})$ before analysis by ion chromatography (IC). The IC was performed using an ICS-900 ion chromatography system (Dionex Corporation) equipped with a dual piston pump, a model AS-DV autosampler, an isocratic column at room temperature, a DS5 conductivity detector, and an AMMS 300 suppressor ( $4 \mathrm{~mm}$ ) for anions and CMMS 300 suppressor $(4 \mathrm{~mm})$ for cations. A Dionex Ion-Pac AS23 analytical column $(4 \times 250 \mathrm{~mm})$ and a guard column $(4 \times 50 \mathrm{~mm})$ were used for anion separations, whereas a Dionex IonPac CS12A analytical column $(4 \times 250 \mathrm{~mm})$ and a guard column $(4 \times 50 \mathrm{~mm})$ were used for cation separations. The eluent consisted of $4.5 \mathrm{mM}$ sodium carbonate and $0.8 \mathrm{mM}$ sodium bicarbonate at a flow rate of $1 \mathrm{~mL} \mathrm{~min}^{-1}$ for anions, and $20 \mathrm{mM}$ metansolfonic acid for cations at the same flow rate. Chromeleon 6.5 chromatography management software was used for system control and data processing. Anions and cations were quantified following a calibration method. Dionex solutions containing seven anions and five cations at different concentrations were taken as standards, and the calibration curves for anions and cations were generated with concentrations ranging from $0.4 \mathrm{mg} \mathrm{L}^{-1}$ to $20 \mathrm{mg} \mathrm{L}^{-1}$ and from $0.5 \mathrm{mg} \mathrm{L}^{-1}$ to $50 \mathrm{mg} \mathrm{L}^{-1}$ of standards, respectively. The Kjeldahl method (ISO 1656) was used for organic nitrogen.

\subsubsection{Brix Content}

Approximately $0.5 \mathrm{~mL}$ of defrosting liquid of the product was used for the determination of the Brix content, carried out using a Hanna Instruments HI 96801 portable digital refractometer.

\subsubsection{Starch}

Starch analysis was performed by chromatographic analysis according to AOAC Official Method 996.11 (University of Florida, IFAS, Bulletin 339-2000 "Starch Gelatinization \& Hydrolysis Method" Boehringer Mannheim, Starch determination, cat. $N^{\circ}$ 207748).

\subsubsection{Quantitative Determination of Sugars by HPLC}

Freeze-dried sweet potato root samples $(0.2 \mathrm{~g})$ were homogenized in demineralized water $(20 \mathrm{~mL})$ with an Ultra Turrax T25 until a uniform consistency was achieved at $1018 \mathrm{~g}$. Samples were filtered in sequence through filter paper (589; Schleicher), and the extracts were further filtered through cellulose acetate syringe filters $(0.45 \mathrm{~mm})$ and analyzed by HPLC. The liquid chromatography apparatus utilized in this analysis was a Jasco X.LC system consisting of a model PU-2080 pump, a model RI-2031 refractive index detector, a model AS-2055 autosampler, and a model CO-2060 column. ChromNAV Chromatography Data System software was used for analysis of the results. The separation of sugars was achieved on a Hyper-Rez XP Carbohydrate $\mathrm{Pb}^{++}$analytical column $(7.7 \times 300 \mathrm{~mm}$; Thermo Scientific, Waltham, MA, USA), operating at $80{ }^{\circ} \mathrm{C}$. Isocratic elution was effected using water at a flow rate of $0.6 \mathrm{~mL} \mathrm{~min}{ }^{-1}$. D-(+)-glucose, $\mathrm{D}$-(-)-fructose, and maltose were quantified by a calibration method. All standards utilized in the experiments were accurately weighed and dissolved in water; the calibration curves were generated with concentrations ranging from 100 to $1000 \mathrm{mg} \mathrm{L}^{-1}$ of standards.

\subsection{Statistical Analysis}

Chemical and morphological data were finally used to construct a constrained UPGMA dendrogram using PAST software v. 3.14 [36], applying the Euclidean similarity index and keeping the position of the samples fixed throughout the tree according to the clustering resulting from the SSR-based dendrogram. To measure the stability of the branches, a statistical bootstrap analysis was conducted with 1000 resampling replicates. 
The complete set of data for each variety was used for random combinations using the bootstrap method. For each variety, a set of 1000 combinations was produced, and the data were analyzed by the PCoA procedure using the software Statgraphics Centurion 18.1.06 (Statgraphics Technologies, Inc.). All qualitative trait data were processed by ANOVA and, in case of significant differences, average values were separated by Tukey HSD test (CoStat 6.400-CoHort Software, CA, USA).

\section{Results and Discussion}

Overall, 117 marker alleles were detected in 11 SSR loci analyzed throughout the accession pool, ranging from a minimum of 6 (J206A) to a maximum of 16 (GDAAS0757), with an average number equal to 10.5 per locus (Table 3 and supplementary Table S1). According to Botstein et al. [33], all examined marker loci were found to be highly informative and variable across the accessions, with a mean PIC value equal to 0.79 , spanning from 0.61 (J206A) to 0.93 (GDAAS0615), as reported in Table 3. Since private polymorphisms are recognized as an efficient molecular tool for food traceability, the presence of marker alleles able to discriminate the accessions according to their putative origin was investigated. As many as 58 out of the total 117 marker alleles scored (Table 3, blue boxes) were exclusively identified only within the foreign accessions pool, but only two of them, i.e., loci IBSSR04 and J116a (Table 3, underlined percentages) were scored in at least $60 \%$ of the accessions. In contrast, six marker alleles were exclusively associated with the Italian pool (Table 3, red boxes) and only one, i.e., locus IBSSR27, was found in at least $60 \%$ of the Italian sweet potatoes (Table 3, underlined percentage).

According to the genetic similarity matrix calculated in all possible pairwise comparisons among the 22 accessions, Dice's coefficient ranged from 0.28 (between BR_78 and BR_30) to 0.97 (between IT_41 and IT_44, Table S2). US_45 resulted to be the most divergent genotype: the average genetic similarity value calculated against the rest of the accessions was as low as 0.41 , highlighting a clear-cut differentiation from the rest of the pool. The mean genetic similarity value calculated among the five Italian accessions was 0.70 . The same value calculated in all pairwise comparisons within the Brazilian accessions was considerably lower (0.54), consistent with the great morphological variability observed within the South American core collection. The accession BR_66 was the most closely related to the Italian clones, scoring an average genetic similarity value of 0.70 and a maximum of 0.74 when compared with IT_44. From the principal coordinate analysis (PCoA), the first coordinate separated a group composed of eight Brazilian entries (namely, BR_25, BR_53, BR_33, BR_32, BR_11, BR_78, BR_79, and BR_80) from a group including all of the Italian clones (Figure 1).

The first principal coordinate also underlined the separation of the two US accessions (US_45 and US_85), according to their contrasting phenotype and in agreement with their low genetic similarity value (0.38). The main result of the variation explained by the second principal coordinate was the split of three Italian accessions showing a cream skin color (namely, IT_44, IT_81, and IT_41) from two Italian accessions distinguishable for their pink skin color (IT_49 and IT_43). This finding was supported not only by a contrasting phenotype, but also by a relatively low estimate of mean genetic similarity (0.60) calculated between these two groups, suggesting a different origin of the Italian accessions. The UPGMA analysis confirmed the sharp detachment, already seen in the genetic similarity matrix (Table S2), of US_45 from the rest of the genotypes (Figure 2A), supported by a bootstrap value of 100 . 
Table 3. Marker allele size, overall allele frequencies (F.o.), allele frequencies in the foreign accessions (F.f.), allele frequencies in the Italian accessions (F.i.), and polymorphism information content (PIC) values are reported for the 11 SSR loci. The blue boxes highlight private marker alleles found only in the foreign accessions, while red boxes denote marker alleles detected only in the Italian accessions. Percentages underlined designate private marker alleles shared by at least $60 \%$ of the foreign samples, as well as private marker alleles shared by at least $60 \%$ of the Italian clones.

\begin{tabular}{|c|c|c|c|c|c|c|c|c|c|c|c|c|c|c|c|c|c|c|c|c|c|c|c|c|c|c|c|c|c|}
\hline \multicolumn{4}{|c|}{ IBSSR04 } & \multicolumn{6}{|c|}{$\mathrm{J} 544 \mathrm{~b}$} & \multicolumn{4}{|c|}{ Ib-255F1 } & \multicolumn{6}{|c|}{ Ib297 } & \multicolumn{4}{|c|}{ Ib286 } & \multicolumn{6}{|c|}{ ibS11 } \\
\hline Size & F.o. & F.f. & F.i. & PIC & Size & F.o. & F.f. & F.i. & PIC & Size & F.o. & F.f. & F.i. & PIC & Size & F.o. & F.f. & F.i. & PIC & Size & F.o. & F.f. & F.i. & PIC & Size & F.o. & F.f. & F.i. & PIC \\
\hline 218 & $18 \%$ & $24 \%$ & $0 \%$ & \multirow{3}{*}{0.75} & 178 & $18 \%$ & $24 \%$ & $0 \%$ & \multirow[b]{2}{*}{0.63} & 237 & $23 \%$ & $24 \%$ & $20 \%$ & & 147 & $5 \%$ & $6 \%$ & $0 \%$ & & 99 & $5 \%$ & $6 \%$ & $0 \%$ & & 227 & $55 \%$ & $41 \%$ & $100 \%$ & \\
\hline 222 & $45 \%$ & $\underline{65 \%}$ & $0 \%$ & & 192 & $18 \%$ & $24 \%$ & $0 \%$ & & 243 & $5 \%$ & $6 \%$ & $0 \%$ & & 151 & $14 \%$ & $18 \%$ & $0 \%$ & & 105 & $32 \%$ & $41 \%$ & $0 \%$ & & 233 & $9 \%$ & $6 \%$ & $20 \%$ & \\
\hline 224 & $18 \%$ & $12 \%$ & $40 \%$ & & 195 & $59 \%$ & $47 \%$ & $100 \%$ & & 251 & $50 \%$ & $53 \%$ & $40 \%$ & & 155 & $64 \%$ & $71 \%$ & $40 \%$ & & 107 & $14 \%$ & $18 \%$ & $0 \%$ & & 236 & $55 \%$ & $53 \%$ & $60 \%$ & \\
\hline 226 & $68 \%$ & $71 \%$ & $60 \%$ & & 198 & $82 \%$ & $76 \%$ & $100 \%$ & & 253 & $45 \%$ & $53 \%$ & $20 \%$ & & 159 & $14 \%$ & $18 \%$ & $0 \%$ & & 109 & $100 \%$ & $100 \%$ & $100 \%$ & & 239 & $32 \%$ & $29 \%$ & $40 \%$ & \\
\hline 228 & $50 \%$ & $47 \%$ & $60 \%$ & & 209 & $82 \%$ & $76 \%$ & $100 \%$ & & 255 & $73 \%$ & $65 \%$ & $100 \%$ & 087 & 161 & $55 \%$ & $41 \%$ & $100 \%$ & 087 & 113 & $77 \%$ & $71 \%$ & $100 \%$ & 077 & 242 & $27 \%$ & $18 \%$ & $60 \%$ & 087 \\
\hline & & & & & & & & & & 261 & $9 \%$ & $12 \%$ & $0 \%$ & & 169 & $5 \%$ & $0 \%$ & $20 \%$ & & 123 & $9 \%$ & $12 \%$ & $0 \%$ & & 251 & $18 \%$ & $24 \%$ & $0 \%$ & \\
\hline & & & & & & & & & & 263 & $32 \%$ & $41 \%$ & $0 \%$ & & 171 & $9 \%$ & $0 \%$ & $40 \%$ & & & & & & & 254 & $59 \%$ & $59 \%$ & $60 \%$ & \\
\hline & & & & & & & & & & 265 & $27 \%$ & $35 \%$ & $0 \%$ & & 175 & $5 \%$ & $6 \%$ & $0 \%$ & & & & & & & 257 & $9 \%$ & $12 \%$ & $0 \%$ & \\
\hline & & & & & & & & & & 267 & $9 \%$ & $0 \%$ & $40 \%$ & & 177 & $27 \%$ & $35 \%$ & $0 \%$ & & & & & & & 260 & $14 \%$ & $18 \%$ & $0 \%$ & \\
\hline & & & & & & & & & & & & & & & 187 & $32 \%$ & $41 \%$ & $0 \%$ & & & & & & & 263 & $9 \%$ & $12 \%$ & $0 \%$ & \\
\hline & & $16 \mathrm{a}$ & & & & & $06 \mathrm{~A}$ & & & & GDA & AS061 & & & & GDAA & AS0757 & & & & IBS & SR27 & & & & & & & \\
\hline 206 & $91 \%$ & $88 \%$ & $100 \%$ & & 130 & $5 \%$ & $6 \%$ & $0 \%$ & 0.01 & 230 & $68 \%$ & $76 \%$ & $60 \%$ & & 290 & $9 \%$ & $12 \%$ & $0 \%$ & & 163 & $10 \%$ & $12 \%$ & $0 \%$ & & & & & & \\
\hline 209 & $32 \%$ & $41 \%$ & $0 \%$ & 0.69 & 133 & $59 \%$ & $53 \%$ & $80 \%$ & & 232 & $5 \%$ & $6 \%$ & $0 \%$ & & 293 & $14 \%$ & $6 \%$ & $40 \%$ & & 165 & $95 \%$ & $88 \%$ & $100 \%$ & 0.88 & & & & & \\
\hline 212 & $55 \%$ & $47 \%$ & $80 \%$ & & 136 & $9 \%$ & $12 \%$ & $0 \%$ & & 234 & $9 \%$ & $12 \%$ & $0 \%$ & 0.93 & \begin{tabular}{|l|}
296 \\
\end{tabular} & $41 \%$ & $53 \%$ & $0 \%$ & & 167 & $10 \%$ & $12 \%$ & $0 \%$ & & & & & & \\
\hline 215 & $82 \%$ & $76 \%$ & $100 \%$ & & & & & & & 236 & $23 \%$ & $24 \%$ & $20 \%$ & & 299 & $5 \%$ & $6 \%$ & $0 \%$ & & 169 & $5 \%$ & $6 \%$ & $0 \%$ & & & & & & \\
\hline 218 & $9 \%$ & $12 \%$ & $0 \%$ & & & & & & & 246 & $9 \%$ & $12 \%$ & $0 \%$ & & 302 & $50 \%$ & $41 \%$ & $80 \%$ & & 171 & $5 \%$ & $0 \%$ & $20 \%$ & & & & & & \\
\hline 221 & $50 \%$ & $\underline{65 \%}$ & $0 \%$ & & & & & & & 248 & $14 \%$ & $18 \%$ & $0 \%$ & & 305 & $27 \%$ & $35 \%$ & $0 \%$ & 0.89 & 177 & $29 \%$ & $29 \%$ & $20 \%$ & & & & & & \\
\hline & & & & & & & & & & 250 & $18 \%$ & $18 \%$ & $20 \%$ & & 308 & $5 \%$ & $6 \%$ & $0 \%$ & & & & & & & & & & & \\
\hline & & & & & & & & & & 256 & $5 \%$ & $0 \%$ & $20 \%$ & & 311 & $14 \%$ & $12 \%$ & $20 \%$ & & & & & & & & & & & \\
\hline & & & & & & & & & & & & & & & 314 & $36 \%$ & $29 \%$ & $60 \%$ & & & & & & & & & & & \\
\hline & & & & & & & & & & & & & & & 317 & $95 \%$ & $100 \%$ & $80 \%$ & & & & & & & & & & & \\
\hline & & & & & & & & & & & & & & & 320 & $9 \%$ & $12 \%$ & $0 \%$ & & & & & & & & & & & \\
\hline & & & & & & & & & & & & & & & 323 & $27 \%$ & $24 \%$ & $40 \%$ & & & & & & & & & & & \\
\hline & & & & & & & & & & & & & & & 326 & $18 \%$ & $6 \%$ & $60 \%$ & & & & & & & & & & & \\
\hline
\end{tabular}




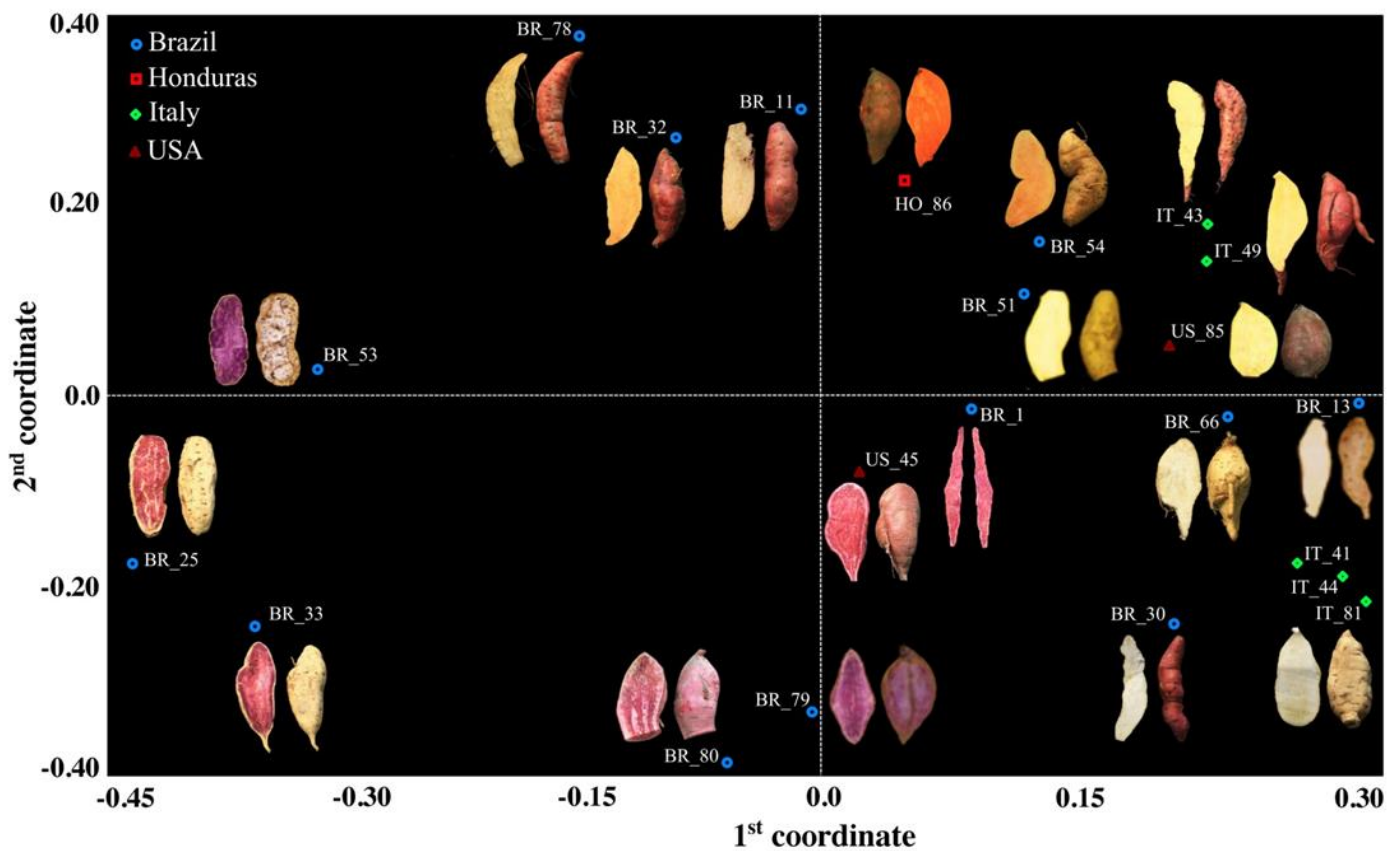

Figure 1. Principal coordinate analysis (PCoA) of the sweet potato core collection based on molecular markers: two-dimensional centroids derived from the genetic similarity estimates computed among accessions in all possible pairwise comparisons using the whole SSR marker data set. The first two coordinates were able to explain $54 \%$ of the total variation, accounting for $31 \%$ and $23 \%$ of the total, respectively. Four different colors have been used to distinguish the accessions based on their geographical origin: blue $=$ Brazil, red $=$ Honduras, green $=$ Italy, and brown $=$ USA .

Four main clustering patterns already highlighted with the PCoA (Figure 1) were also observed throughout the dendrogram (Figure 2 panel A), with bootstrap values always higher than $90 \%$. In detail, BR_79 and BR_80 grouped together and scored the 91\% of similarity; BR_33, BR_25, and BR_53 shared a mean genetic similarity value of $82 \%$; IT_44, IT_41, and IT_81 showed, on average, $88 \%$ the genetic similarity and, finally, BR_11 grouped with BR_78 according to a genetic similarity of $78 \%$. In particular, it is worth highlighting that although the five Italian accessions were all part of the same macrobranch of the tree, they subclustered into two groups, according to what was observed in the PCoA analysis. In fact, in the PCoA, the second coordinate alone explained $23 \%$ of the total variation, clearly separating IT_44, IT_41, and IT_81 from a second group including IT_43 and IT_49 (Figure 1). A noteworthy consideration involving BR_66 is the close association between this Brazilian accession and the first group of Italian accessions in both the PCoA and the UPGMA tree, with a similarity value of 0.74 .

The $\Delta \mathrm{K}$ criterion suggested by Evanno et al. [41] gave the highest value for the SSR analysis at three groups (for $K=3, \Delta K$ resulted 58.53, Figure S1). According to this estimate, the whole group putatively originated from three ancestral genotypes (indicated in grey, orange, and blue in Figure 2B). One vertical histogram for each accession, conveniently divided into $K=3$ colored segments, has been used to represent the estimated membership in each hypothesized ancestral genotype, and $90 \%$ was the threshold set for the admixed ancestry (Figure 2B). This finding seems to be in agreement with those reported by Roullier et al. ([45] Figure 2 in Appendix S1) and Wadl et al. [8], both supporting the $K=3$ in the sweet potato clones from tropical America. Overall, one of the three ancestors (the one in grey) was predominant: 13 samples from USA, Honduras, Italy, and Brazil showed a membership to this ancestral genotype higher than $95 \%$, suggesting a probable common origin. Five accessions (BR_66, IT_81, BR_53, BR_79, and BR_80) were admixed and one of the three ancestors (the one in grey) was always recurrent; interestingly, no example of hybridization between the other two ancestors (blue and orange, Figure 2) was observed. 


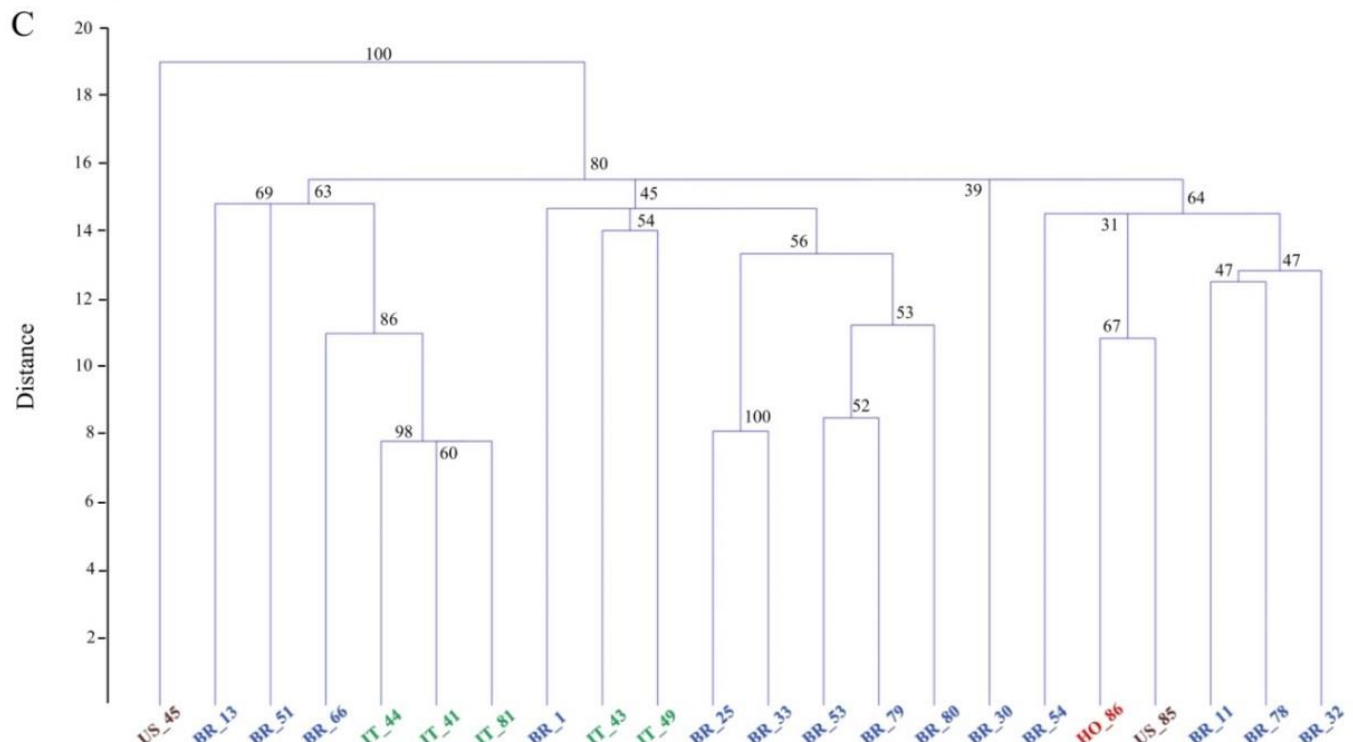

B
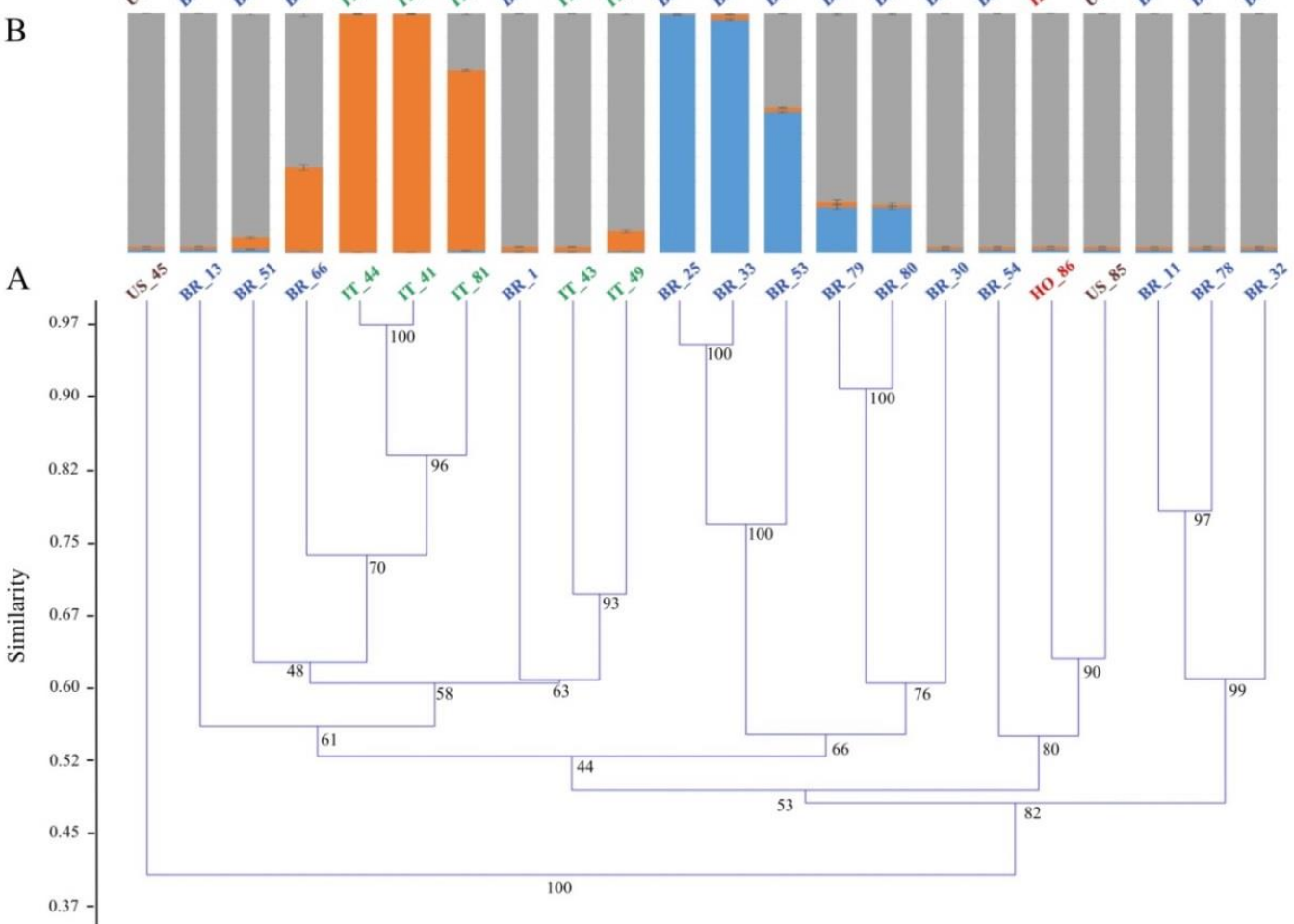

Figure 2. Genetic structure analysis of the sweet potato core collection: (A) The unweighted pair group method with arithmetic average means (UPGMA) tree of the genetic similarity estimates computed among pairwise comparisons of sweet potato accessions using the whole simple sequence repeat (SSR) marker data set, with nodes of the main subgroups supported by bootstrap values. The color scheme for this figure is the same as that used in Figure 1 (Blue = Brazil, red = Honduras, green = Italy, and brown = USA). (B) Population genetic structure of a core collection of $N=22$ sweet potato accessions estimated using 11 microsatellite markers. Each sample is represented by a vertical bar partitioned into $K=3$ colored segments representing the estimated membership. The proportion of ancestry (\%) is reported on the ordinate axis, and the identification number of each accession is indicated below each histogram. (C) The unweighted pair group method with arithmetic average means (UPGMA)-constrained tree was built by applying the Euclidean similarity index and using the morpho-qualitative measurements of a subset of the I. batatas core collection. The positions of the samples throughout the dendrogram were kept fixed according to those ones resulting from the dendrogram in Figure 2A, and the bootstrap values supporting each node of the main subgroups were calculated. 
In detail, two of three Italian accessions characterized by a cream skin color (IT_44 and IT_41) and strictly associated with the same branch of the UPGMA tree (similarity $=0.97$ ) also shared the same marker allele cluster, both with accession scores of individual membership higher than $99 \%$. Although these two Italian accessions were collected in two different areas, these results suggest a case of synonymy and we may suppose that the same genotype is cultivated in different regions with a different name. IT_81 and BR_66, although counted as admixed, shared the same ancestral genotype as IT_44 and IT_41, with percentages of 75\% and 35\%, respectively. Considering the PCoA and the UPGMA tree, it is probable that all four shared the same ancestral genotype (the one indicated in orange), and it is not to be ruled out that the three Italian accessions derived from BR_66. However, it is possible that BR_66 has undergone continuous events of hybridization with individuals descending from the "grey" progenitor, which would explain the admixed pattern of this Brazilian accession. In contrast, the three Italian accessions, whose memberships ranged from 75\% (IT_81) to 99\% (IT_44 and IT_41) may have preserved their "ancestral purity" thanks to repeated crosses with accessions of the same lineage or to asexual propagation breeding schemes. A second cluster included BR_25 and BR_33 (membership > 97\%) and, to a lesser extent, BR_53 (membership = 59\%), according to their sharp detachment from the rest of the pool highlighted by the PCoA analysis. The remaining accessions, including two Italian accessions (IT_49 and IT_43), were all part of a third cluster, except for BR_79 and BR_80, which were admixed (Figure 2B). The Euclidean-index-based UPGMA dendrogram emphasized the clear-cut detachment of US_45 from the rest of the pool (Figure 2C), as previously established by the SSR-based UPGMA (Figure 2A). In this case, the bootstrap support was $100 \%$. The other samples were all clustered in three main branches, with a bootstrap value of $80 \%$. In the first branch, BR_79, BR_80, BR_33, BR_25, and BR_53 clustered together with IT_43, IT_49, and BR_1. This finding was different from that observed in the SSR-based UPGMA tree (Figure 2A), where these two subgroups clustered separately, and it was not consistent with the PCoA analysis and the morphological data (Figure 1). Nevertheless, it must be noted that in the morphological and chemical-marker-based dendrogram (Figure 2C), the bootstrap support of this specific node was quite low (45\%). Moreover, despite the different clusterization highlighted in the two UGPMA trees (Figure 2A,C), the two subgroups maintained the same composition. In particular, all of the samples in the first subgroups (BR_79, BR_80, BR_33, BR_25, and BR_53) were characterized by a typical purple color of flesh that was not detected in other samples. This observation, along with a full or partial membership to the same cluster (Figure 2 panel B), reinforces the hypothesis of a common ancestor for this group of samples, in agreement with their geography. Regarding the second subgroup (IT_43, IT_49, and BR_1), it is very hard to make hypotheses about its origin, although genetic data would presuppose a certain degree of kinship with the other three Italian accessions. Considering the second main branch of the Euclidean-distance-based UPGMA, two considerations are needed. First, IT_44, IT_41,IT_81, and BR_66 grouped together according to all the previous analyses (bootstrap support $86 \%$ ). The fact that the genetic and the morpho-agronomic markers led to identical results may suggest that this first group of Italian genotypes was descended from BR_66, as initially predicted on the basis of their highly similar morphology (Figure 1). All the accessions were also analyzed by means of morpho-agronomic qualitative markers (Table 4). 
Table 4. Qualitative measurements performed on the sweet potato accessions.

\begin{tabular}{|c|c|c|c|c|c|c|c|c|c|c|c|c|c|}
\hline Genotype & $\begin{array}{c}\mathrm{K} \\
(\mathrm{mg} / \mathrm{kg} \mathrm{dw})\end{array}$ & $\begin{array}{c}\mathrm{Mg} \\
(\mathrm{mg} / \mathrm{kg} \mathrm{dw})\end{array}$ & $\begin{array}{c}\mathrm{Ca} \\
(\mathrm{mg} / \mathrm{kg} \mathrm{dw})\end{array}$ & $\begin{array}{c}\text { Total Soluble Solids } \\
\text { ( }{ }^{\circ} \text { Brix) }\end{array}$ & $\begin{array}{c}\text { TP } \\
\left(\mathrm{mg} \mathrm{GAE} \mathrm{kg}^{-1} \mathrm{fw}\right)\end{array}$ & $\begin{array}{c}\text { TAA } \\
\left(\mathrm{mg} \mathrm{Fe}^{2+} \mathrm{E} \mathrm{kg}^{-1} \mathrm{fw}\right)\end{array}$ & $\begin{array}{l}\beta \text {-Carotene } \\
(\mathrm{mg} / \mathrm{kg} \mathrm{fw})\end{array}$ & $\begin{array}{c}\text { Vit C } \\
(\mathrm{mg} / \mathrm{kg} \mathrm{dw})\end{array}$ & $\begin{array}{c}\text { Sucrose } \\
(\mathrm{mg} / \mathrm{kg} \mathrm{dw})\end{array}$ & $\begin{array}{c}\text { Glucose } \\
\text { (mg/k dw) }\end{array}$ & $\begin{array}{c}\text { Fructose } \\
(\mathrm{mg} / \mathrm{kg} \mathrm{dw})\end{array}$ & $\begin{array}{l}\text { Starch } \\
(\%)\end{array}$ & $\begin{array}{c}\text { Dry Matter } \\
(\%)\end{array}$ \\
\hline US_45 & $7381 \mathrm{klm}$ & 2426 bcde & $1810 \mathrm{abc}$ & $9 \mathrm{bc}$ & $6442 \mathrm{a}$ & $6706 \mathrm{a}$ & n.d. & $658 c$ & 364301 & $35280 \mathrm{~cd}$ & 33561 b & $81 \mathrm{a}$ & $36 \mathrm{ab}$ \\
\hline BR_79 & $12151 \mathrm{~b}$ & 1841 def & $2481 \mathrm{ab}$ & $12 \mathrm{a}$ & $2875 \mathrm{bc}$ & $2563 \mathrm{~cd}$ & n.d. & $2967 \mathrm{ab}$ & 109542 defg & $12903 \mathrm{jklm}$ & 11357 fghi & $71 \mathrm{ab}$ & $37 \mathrm{ab}$ \\
\hline BR_80 & $5907 \mathrm{n}$ & 2181 cde & $2405 \mathrm{ab}$ & $11 \mathrm{ab}$ & $2369 \mathrm{bc}$ & $2599 \mathrm{~cd}$ & n.d. & $3966 \mathrm{ab}$ & $93156 \mathrm{fghi}$ & 9487 klmn & 8501 fghi & $74 \mathrm{ab}$ & $43 \mathrm{a}$ \\
\hline BR_33 & $6828 \mathrm{~lm}$ & $1460 \mathrm{ef}$ & $1582 \mathrm{c}$ & $8 c$ & $1753 \mathrm{c}$ & $2095 \mathrm{~cd}$ & n.d. & $3887 \mathrm{ab}$ & 374641 & $26310 \mathrm{de}$ & $29451 \mathrm{bcd}$ & $83 a$ & $36 \mathrm{ab}$ \\
\hline BR_25 & $7074 \mathrm{~lm}$ & $1580 \mathrm{ef}$ & $2104 \mathrm{ab}$ & $9 \mathrm{bc}$ & $3240 \mathrm{bc}$ & $3578 \mathrm{bc}$ & n.d. & $2988 \mathrm{ab}$ & $55692 \mathrm{kl}$ & $31784 \mathrm{~cd}$ & $31623 \mathrm{bc}$ & $72 \mathrm{ab}$ & $36 \mathrm{ab}$ \\
\hline BR_53 & $8965 \mathrm{~g}$ & 1732 def & $2308 \mathrm{ab}$ & $11 \mathrm{ab}$ & 3358 bc & $2869 \mathrm{~cd}$ & n.d. & $1933 \mathrm{bc}$ & 116776 cde & 21199 efg & 22460 de & $70 \mathrm{~b}$ & $34 \mathrm{~b}$ \\
\hline BR_13 & $7328 \mathrm{klm}$ & $2640 a b c$ & $1981 \mathrm{abc}$ & $9 \mathrm{bc}$ & $1839 \mathrm{c}$ & $2210 \mathrm{~cd}$ & n.d. & $2950 \mathrm{~b}$ & 106360 def & $8561 \mathrm{lmn}$ & 6028 hij & $65 \mathrm{bc}$ & $32 \mathrm{~b}$ \\
\hline BR_1 & 5316 no & $1484 \mathrm{ef}$ & $1908 \mathrm{abc}$ & $11 \mathrm{ab}$ & $4425 \mathrm{ab}$ & $4651 \mathrm{~b}$ & n.d. & 4682 a & 81680 hij & $21667 \mathrm{efg}$ & 15816 ef & $69 \mathrm{~b}$ & $36 \mathrm{ab}$ \\
\hline BR_66 & $10647 \mathrm{de}$ & $2270 \mathrm{bcd}$ & $1795 \mathrm{bc}$ & $13 \mathrm{a}$ & $2078 \mathrm{bc}$ & $2156 \mathrm{~cd}$ & 23.8 & $2305 \mathrm{~b}$ & 149539 a & $6364 \mathrm{mn}$ & 6803 ij & $64 \mathrm{bc}$ & $42 \mathrm{a}$ \\
\hline IT_44 & $8045 \mathrm{ij}$ & $2658 \mathrm{abc}$ & $1922 \mathrm{abc}$ & $9 \mathrm{bc}$ & $875 c$ & $834 \mathrm{e}$ & n.d. & $1690 \mathrm{bc}$ & 109205 def & $4396 \mathrm{lmn}$ & $3763 \mathrm{j}$ & $79 \mathrm{ab}$ & $37 \mathrm{ab}$ \\
\hline IT_41 & $10626 \mathrm{de}$ & 2156 cde & $1709 \mathrm{bc}$ & $10 \mathrm{~b}$ & $1595 \mathrm{c}$ & $1335 \mathrm{de}$ & n.d. & $2112 \mathrm{~b}$ & $99035 \mathrm{fg}$ & $8673 \mathrm{lmn}$ & 7189 hij & $83 a$ & $37 \mathrm{ab}$ \\
\hline IT_81 & $12176 \mathrm{~b}$ & $2697 a b c$ & $1925 \mathrm{abc}$ & $10 \mathrm{~b}$ & $1067 \mathrm{c}$ & $862 \mathrm{e}$ & n.d. & $2544 \mathrm{~b}$ & $124873 \mathrm{bcd}$ & $5007 \mathrm{n}$ & $3671 \mathrm{j}$ & $72 \mathrm{ab}$ & $36 \mathrm{ab}$ \\
\hline BR_51 & $9403 \mathrm{~g}$ & $2056 \mathrm{bcd}$ & $1816 \mathrm{abc}$ & $9 \mathrm{bc}$ & $1186 \mathrm{c}$ & $2019 \mathrm{~cd}$ & 34.2 & $3856 \mathrm{ab}$ & 113505 def & 46730 a & $46568 \mathrm{a}$ & $70 \mathrm{~b}$ & $30 \mathrm{~b}$ \\
\hline IT_43 & $15129 a$ & 1729 cde & $1954 \mathrm{abc}$ & $11 \mathrm{ab}$ & 2085 bc & $1906 \mathrm{de}$ & n.d. & $1867 \mathrm{bc}$ & $144240 \mathrm{ab}$ & $12253 \mathrm{ijklm}$ & $10429 \mathrm{fgh}$ & $75 \mathrm{ab}$ & $34 \mathrm{~b}$ \\
\hline IT_49 & $7855 \mathrm{ijk}$ & $2302 \mathrm{bcd}$ & $1563 \mathrm{c}$ & $10 \mathrm{~b}$ & $1453 \mathrm{c}$ & $1607 \mathrm{de}$ & 208 & $1389 \mathrm{bc}$ & $92224 \mathrm{ghi}$ & $36301 \mathrm{bc}$ & $24108 \mathrm{~cd}$ & $80 \mathrm{a}$ & $30 \mathrm{~b}$ \\
\hline BR_30 & $6766 \mathrm{~lm}$ & 2118 cde & $1848 \mathrm{bc}$ & $8 c$ & $1657 \mathrm{c}$ & $1743 \mathrm{de}$ & 90.8 & $1427 \mathrm{bc}$ & $68226 \mathrm{jk}$ & $45548 \mathrm{a}$ & $33478 \mathrm{~b}$ & $70 \mathrm{~b}$ & $31 \mathrm{~b}$ \\
\hline BR_54 & $6666 \mathrm{~m}$ & $2619 a b c$ & $2624 \mathrm{a}$ & $9 \mathrm{bc}$ & $1317 \mathrm{c}$ & $1577 \mathrm{de}$ & 571 & $2285 \mathrm{~b}$ & $138292 \mathrm{bc}$ & 13282 hijk & $10709 \mathrm{fgh}$ & $78 \mathrm{ab}$ & $37 \mathrm{ab}$ \\
\hline HO_86 & $11914 b c$ & $2192 \mathrm{bcd}$ & $2282 \mathrm{ab}$ & $9 \mathrm{bc}$ & $1189 \mathrm{c}$ & $1179 \mathrm{de}$ & 512 & $2477 \mathrm{~b}$ & $95520 \mathrm{fgh}$ & $42100 \mathrm{ab}$ & 45446 a & $52 \mathrm{c}$ & $36 \mathrm{ab}$ \\
\hline US_85 & $8970 \mathrm{~g}$ & 2023 cde & $2264 \mathrm{ab}$ & $8 \mathrm{c}$ & $720 \mathrm{c}$ & $799 \mathrm{e}$ & n.d. & $1595 \mathrm{c}$ & $69641 \mathrm{jk}$ & 25645 def & $30837 \mathrm{bc}$ & $60 \mathrm{c}$ & $36 \mathrm{ab}$ \\
\hline BR_32 & $8096 \mathrm{hi}$ & 1645 def & $2298 \mathrm{ab}$ & $11 \mathrm{ab}$ & $1551 \mathrm{c}$ & $1516 \mathrm{de}$ & 811 & $4709 \mathrm{a}$ & $138295 \mathrm{bc}$ & 17282 ghij & 14933 efg & $72 \mathrm{ab}$ & $32 \mathrm{~b}$ \\
\hline BR_11 & $10431 \mathrm{f}$ & $1452 \mathrm{f}$ & $1763 \mathrm{bc}$ & $9 \mathrm{bc}$ & $2477 b c$ & $1073 \mathrm{e}$ & n.d. & $3087 \mathrm{ab}$ & $88841 \mathrm{ghi}$ & 19294 efgh & $14664 \mathrm{efg}$ & $72 \mathrm{ab}$ & $35 \mathrm{~b}$ \\
\hline BR_78 & $6850 \mathrm{~lm}$ & $2352 \mathrm{bcd}$ & $1808 \mathrm{bc}$ & $10 \mathrm{~b}$ & $2119 b c$ & 1809 de & n.d. & $1256 \mathrm{c}$ & 100268 efg & 17742 fghi & $13919 \mathrm{fg}$ & $70 \mathrm{~b}$ & $42 \mathrm{a}$ \\
\hline
\end{tabular}

Within each parameter, values without common letters significantly differed at $P<0.05$ according to Tukey's HSD test (n.d., not determined). 
In addition to genetic characteristics, quality traits are generally preferred for nutritive value and market demand [46-48]. With regard to the qualitative aspects, the dataset obtained for the different parameters is summarized in Figure 3 by multivariate analysis.

A

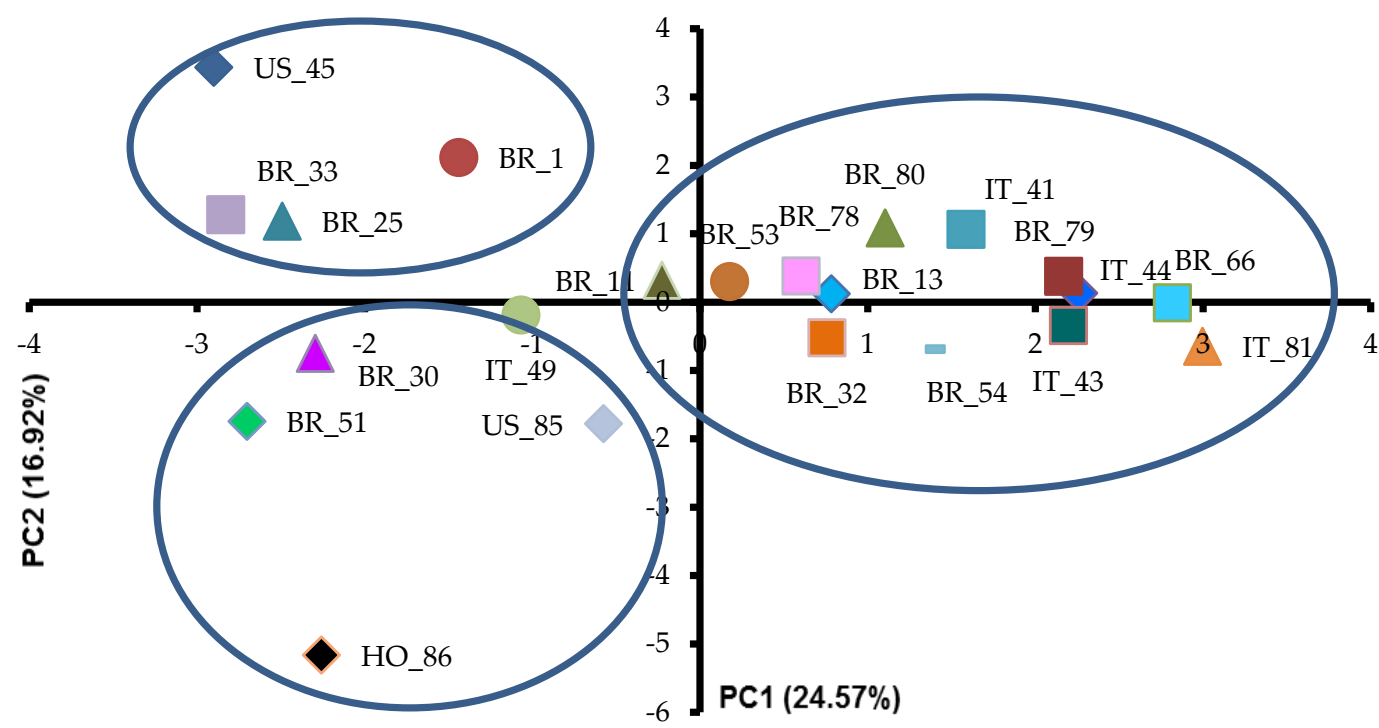

B

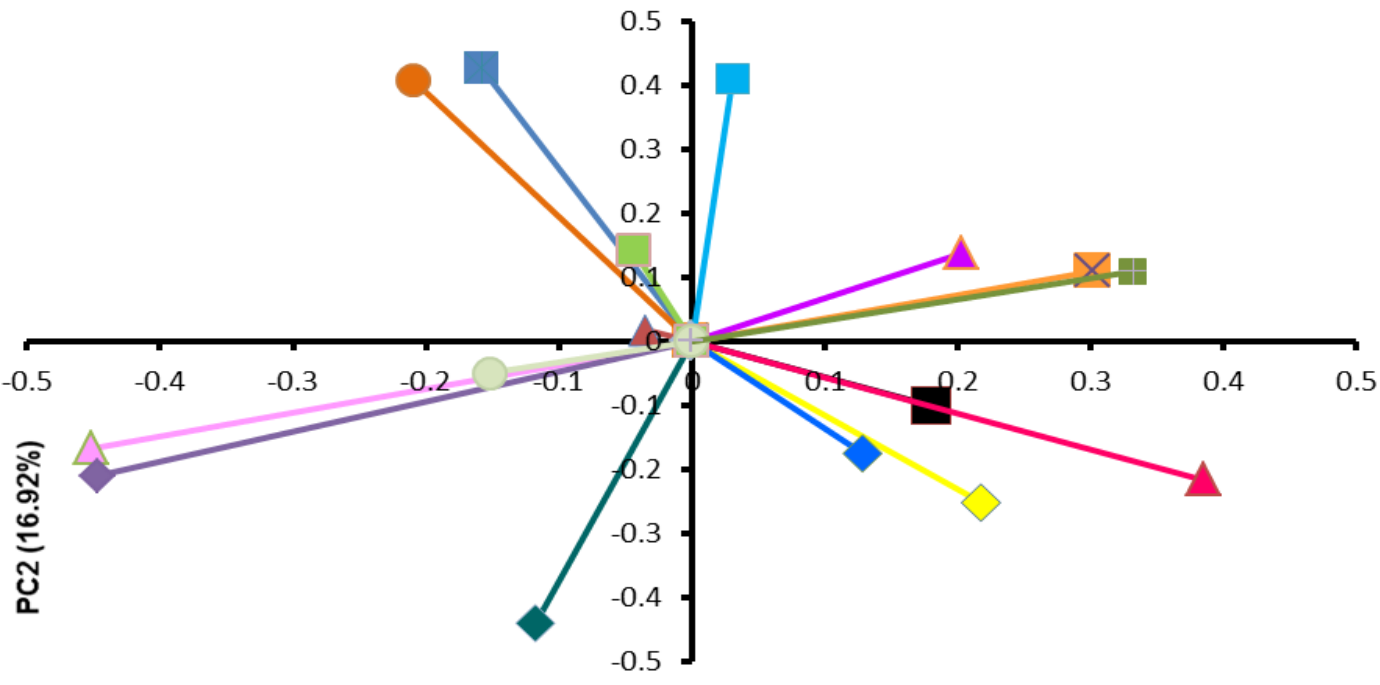

PC1 (24.57\%)
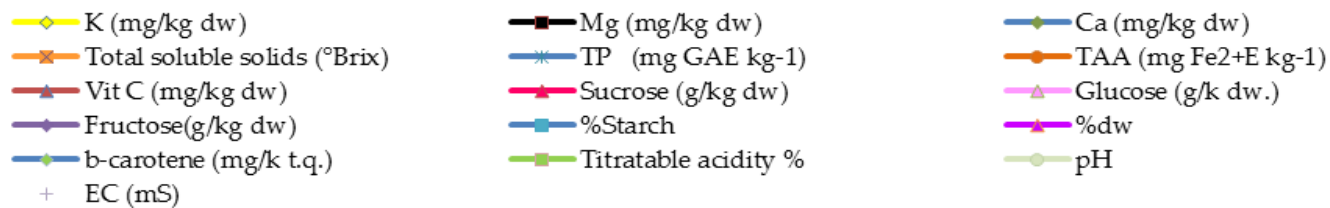

Figure 3. Principal components analysis (PCA) of the sweet potato core collection based on qualitative traits: (A) Score plot of the first two principal components (PC1 and PC2) for the 22 sweet potatoes. (B) Eigenvectors of the variables measured for the first two principal components. Loadings (eigenvalues) for the first and second principal components were equal to $25 \%$ and $17 \%$, respectively. TP: total phenols; TAA: total antioxidant activity; dw: dry weight.

The first identified the different genotypes positioned on the basis of the measured qualitative characteristics, whereas the second vectorially highlighted the main qualitative traits that determined the genotype positioning. The results obtained from this elaboration allowed us to identify interesting cues 
regarding grouping of the different genotypes according to their qualitative peculiarities. In particular, it was possible to group the 22 genotypes into three macrogroups (A, B, and C). Group A comprised those genotypes characterized by a high anthocyanin content in both the skin and the flesh (US_45, BR_1, BR_33, and BR_25). The genotypes belonging to this group were characterized by high total antioxidant capacity and high total polyphenol content (Figure 3). The anthocyanins belong to the antioxidant family, in particular to the polyphenols, and have positive effects on human health [49]. Anthocyanin composition was determined in purple-fleshed sweet potatoes [50,51], highlighting that cyanidin and peonidin glycosides acylated with phenolic acids were the primary anthocyanin components. The second group, B, comprised genotypes phenotypically characterized by high beta-carotene content, thus featuring orange pulp, and by high simple sugar concentrations (BR_51, BR_30, IT_49, US_85, and HO_86). Carotenoids are secondary plant compounds that form lipid-soluble yellow, orange, and red pigments. Carotene-rich vegetables are associated with decreased risk of chronic diseases related to vision, skin, infection, and reproduction, in addition to being active oxygen species scavengers [52]. The most abundant carotenoid in sweet potato roots is usually $\beta$-carotene, which comprises more than $77 \%$ of total carotenoid content and can reach more than $99 \%$ in sweet potatoes characterized by orange flesh [53]. The colored genotypes considered in this experiment were characterized by a $\beta$-carotene content ranging from 23.8 to $811 \mu \mathrm{g} \mathrm{g}^{-1}$. This range was wider than those measured by Simonne et al. [54] (1-190 $\left.\mu \mathrm{g} \mathrm{g}^{-1}\right)$ and by Grace et al. [50] (1-253.3 $\left.\mu \mathrm{g} \mathrm{g}^{-1}\right)$ in several sweet potato varieties. Finally, group C contained genotypes characterized by different flesh colors, but they shared a high content of sucrose and minerals (BR_32, BR_54, IT_43, and IT_81) or a high percentage of dry matter, soluble solids, and starch (BR_53, BR_78, BR_80, IT_41, BR_79, and BR_66). The high presence of starch and sucrose makes these varieties particularly sweet after slow cooking processes (i.e., boiling, oven, steam), following the production of maltose [3,55]. Genotypes belonging to group A and B may be more suitable for faster cooking methods (i.e., frying) because they are characterized by less starch, and they are more appealing for the consumer from a color point of view.

As shown from the comparison between grouping results of the core collection of sweet potato accessions (see Figures 1 and 3), some inconsistencies arose between the clustering based on molecular markers and that derived from qualitative parameters. This was understandable since both the molecular markers and qualitative parameters evaluated in this study not only represented a subset of the evaluable genotypic and phenotypic traits, but also because they did not show any known linkage. Consequently, a full overlap with what was detected by the principal components based on qualitative traits is not possible, as demonstrated by the centroids derived from the principal coordinates of molecular markers. An example of this behavior can be found between IT_43 and IT_49: these genotypes were grouped together based on molecular markers, whereas they differed according to the qualitative profiles (e.g., the former scored a higher concentration of potassium, whereas the latter a higher content of simple sugars).

\section{Conclusions}

We investigated, for the first time, the genetic structure and qualitative composition of the principal Italian sweet potato clones, along with their relatedness to a core collection of accessions from Central and Southern America. It is worth mentioning that the sweet potato accessions analyzed in this study represent the most cultivated clones in Italy and, to the best of our knowledge, no other locally adapted varieties are commercially available to Italian farmers. In fact, these materials, grown mainly in the Veneto region, are known to possess a high adaptation to the natural and anthropological environment in which they have been introduced and are still cultivated.

From the molecular analyses, Italian accessions were sub-clustered into two groups and were found to be genetically very similar to the South American germplasm. This finding was also supported by the morphological and chemical measurements affecting their principal qualitative traits.

Summarizing our results and considering both the morphological and qualitative and the genetic-molecular data, it is evident how the combination of these two different approaches was very 
effective in differentiating or clustering the different clonal genotypes, as expected by their geographical origin or their phenotypic characteristics. Moreover, because the molecular and the chemical results were often comparable, it was possible to make robust speculations on the common origins of sweet potato accessions. The experiment demonstrated not only a good relationship between genetic and morphological and qualitative aspects, but also allowed us to indirectly highlight the good level of adaptation of South American genotypes to European conditions. This last information allows us to suggest that breeders use South American germplasm, characterized above all by colored pulp, for the constitution of new genotypes in Europe, useful for the renewal and innovation of the European market as well as for providing new opportunities for farmers. On the whole, this information could be exploited by both breeders and farmers to detect and protect commercial varieties, and hence to certify the genetic identity of their propagation materials and overall quality of their food derivatives.

Supplementary Materials: The following are available online at http://www.mdpi.com/2073-4425/10/11/840/s1, Figure S1: Definition of the number of ancestral sweet potato genotypes. Mean $\Delta K$ is calculated as L" $(\mathrm{K}) /(\mathrm{SD}(\mathrm{L}(\mathrm{K})))$ following Evanno et al. (Evanno et al. 2005), where mean LnP(D) \pm SD over 10 runs is a function of $K$, being $L^{\prime}(K)$ $=\Delta \mathrm{LnP}(\mathrm{D})$, Table S1: SSR data recorded for the different sweet potato genotypes, Table S2: Genetic similarity matrix for the sweet potato accessions.

Author Contributions: Conceptualization, C.N., G.B. and P.S.; methodology, A.C.G., F.P.; validation, C.N., G.B. and P.S.; formal analysis, A.C.G., F.P. and C.N.; investigation, A.C.G., F.P. and C.N.; resources, G.B. and P.S.; data curation, A.C.G., F.P., C.N., G.B. and P.S.; writing-original draft preparation, A.C.G., F.P. and C.N.; writing-review and editing, F.P. and C.N.; supervision, G.B. and P.S.

Funding: This research received no external funding.

Conflicts of Interest: The authors declare no conflict of interest.

\section{References}

1. Woolfe, J.A. Sweet Potato: An Untapped Food Resource; Cambridge University Press: Cambridge, UK, 1992; Volume 366-372.

2. CBI Market Intelligence CBI Product Factsheet: Fresh Sweet Potatoes in Europe; CBI Market Intelligence: The Hague, The Netherlands, 2015.

3. Nicoletto, C.; Vianello, F.; Sambo, P. Effect of different home-cooking methods on textural and nutritional properties of sweet potato genotypes grown in temperate climate conditions. J. Sci. Food Agric. 2018, 98, 574-581. [CrossRef] [PubMed]

4. Veasey, E.A.; Borges, A.; Rosa, M.S.; Queiroz-Silva, J.R.; Bressan, E.D.A.; Peroni, N. Genetic diversity in Brazilian sweet potato (Ipomoea batatas (L.) Lam., Solanales, Convolvulaceae) landraces assessed with microsatellite markers. Genet. Mol. Biol. 2008, 31, 725-733. [CrossRef]

5. Roullier, C.; Rossel, G.; Tay, D.; McKey, D.; Lebot, V. Combining chloroplast and nuclear microsatellites to investigate origin and dispersal of New World sweet potato landraces. Mol. Ecol. 2011, 20, 3963-3977. [CrossRef] [PubMed]

6. Roullier, C.; Duputié, A.; Wennekes, P.; Benoit, L.; Fernández Bringas, V.M.; Rossel, G.; Tay, D.; McKey, D.; Lebot, V. Disentangling the Origins of Cultivated Sweet Potato (Ipomoea batatas (L.) Lam.). PLoS ONE 2013, 8, e62707. [CrossRef]

7. Yang, X.S.; Su, W.J.; Wang, L.J.; Lei, J.; Chai, S.S.; Liu, Q. chang Molecular diversity and genetic structure of 380 sweetpotato accessions as revealed by SSR markers. J. Integr. Agric. 2015, 14, 633-641. [CrossRef]

8. Wadl, P.A.; Olukolu, B.A.; Branham, S.E.; Jarret, R.L.; Yencho, G.C.; Jackson, D.M. Genetic Diversity and Population Structure of the USDA Sweetpotato (Ipomoea batatas) Germplasm Collections Using GBSpoly. Front. Plant Sci. 2018, 9, 1-13. [CrossRef]

9. Austin, D. The taxonomy, evolution and genetic diversity of sweet potatoes and related wild species. In Exploration, Maintenance and Utilization of Sweet Potato Genetic Resources: Report of the First Sweet Potato Planning Conference; International Potato Center (CIP): Lima, Perù, 1987.

10. Wang, Z.; Li, J.; Luo, Z.; Huang, L.; Chen, X.; Fang, B.; Li, Y.; Chen, J.; Zhang, X. Characterization and development of EST-derived SSR markers in cultivated sweetpotato (Ipomoea batatas). BMC Plant Biol. 2011, 11. [CrossRef] 
11. Gao, M.; Ashu, G.M.; Stewart, L.; Akwe, W.A.; Njiti, V.; Barnes, S. Wx intron variations support an allohexaploid origin of the sweetpotato [Ipomoea batatas (L.) Lam]. Euphytica 2011, 177, 111-133. [CrossRef]

12. Magoon, M.; Krishnan, R.; Vijaya Bai, K. Cytological evidence on the origin of sweet potato. Theor. Appl. Genet. 1970, 40, 360-366. [CrossRef]

13. Soltis, D.E.; Soltis, P.S. Polyploidy: Recurrent formation and genome evolution. Trends Ecol. Evol. 1999, 14, 348-352. [CrossRef]

14. Silva Ritschel, P.; Huamán, Z. Variabilidade morfologica da coleçao de germoplasma de batata doce da Embrapa Centro Nacional de Pesquisas de Hortaliças. Pesqui. Agropecu. Bras. 2002, 37, 485-492. [CrossRef]

15. Palumbo, F.; Galla, G.; Martinez-Bello, L.; Barcaccia, G. Venetian Local Corn (Zea mays L.) Germplasm: Disclosing the Genetic Anatomy of Old Landraces Suited for Typical Cornmeal Mush Production. Diversity 2017, 9, 32. [CrossRef]

16. Cruz, C.D.; Carneiro, P.C.S.; Regazzi, A.J. Modelos Biométricos Aplicados ao Melhoramento Genético-Volume 1, 3rd ed.; Editora UFV: Viçosa, Brazil, 2012; ISBN 9788572694339.

17. Palumbo, F.; Galla, G.; Barcaccia, G. Developing a molecular identification assay of old landraces for the genetic authentication of typical agro-food products: The case study of the barley "agordino". Food Technol. Biotechnol. 2017, 55, 29-39. [CrossRef] [PubMed]

18. Crinò, P.; Pagnotta, M.A. Phenotyping, genotyping, and selections within italian local landraces of romanesco globe artichoke. Diversity 2017, 9, 14. [CrossRef]

19. Mercati, F.; Longo, C.; Poma, D.; Araniti, F.; Lupini, A.; Mammano, M.M.; Fiore, M.C.; Abenavoli, M.R.; Sunseri, F. Genetic variation of an Italian long shelf-life tomato (Solanum lycopersicon L.) collection by using SSR and morphological fruit traits. Genet. Resour. Crop Evol. 2014, 62, 721-732. [CrossRef]

20. Andreakis, N.; Kooistra, W.H.C.F.; Procaccini, G. High genetic diversity and connectivity in the polyploid invasive seaweed Asparagopsis taxiformis (Bonnemaisoniales) in the Mediterranean, explored with microsatellite alleles and multilocus genotypes. Mol. Ecol. 2009, 18, 212-226. [CrossRef]

21. Cordeiro, G.M.; Pan, Y.B.; Henry, R.J. Sugarcane microsatellites for the assessment of genetic diversity in sugarcane germplasm. Plant Sci. 2003, 165, 181-189. [CrossRef]

22. Pinto, L.R.; Oliveira, K.M.; Marconi, T.; Garcia, A.A.F.; Ulian, E.C.; De Souza, A.P. Characterization of novel sugarcane expressed sequence tag microsatellites and their comparison with genomic SSRs. Plant Breed. 2006, 125, 378-384. [CrossRef]

23. Babaei, A.; Tabaei-Aghdaei, S.R.; Khosh-Khui, M.; Omidbaigi, R.; Naghavi, M.R.; Esselink, G.D.; Smulders, M.J.M. Microsatellite analysis of Damask rose (Rosa damascena Mill.) accessions from various regions in Iran reveals multiple genotypes. BMC Plant Biol. 2007, 7, 1-6. [CrossRef]

24. Veasey, E.A.; Silva, J.R.D.Q.; Rosa, M.S.; Borges, A.; Bressan, E.D.A.; Peroni, N. Phenology and morphological diversity of sweet potato (Ipomoea batatas) landraces of the Vale do Ribeira. Sci. Agric. 2007, 64, 416-427. [CrossRef]

25. Yada, B.; Tukamuhabwa, P.; Alajo, A.; Mwanga, R.O.M. Morphological characterization of Ugandan sweetpotato germplasm. Crop Sci. 2010, 50, 2364-2371. [CrossRef]

26. Elameen, A.; Larsen, A.; Klemsdal, S.S.; Fjellheim, S.; Sundheim, L.; Msolla, S.; Masumba, E.; Rognli, O.A. Phenotypic diversity of plant morphological and root descriptor traits within a sweet potato, Ipomoea batatas (L.) Lam., germplasm collection from Tanzania. Genet. Resour. Crop Evol. 2011, 58, 397-407. [CrossRef]

27. Karuri, H.; Ateka, E.; Amata, R.; Nyende, A.; Muigai, A.; Mwasame, E.; Gichuki, S. Evaluating diversity among Kenyan sweet potato genotypes using morphological and SSR markers. Int. J. Agric. Biol. 2010, 12, $33-38$.

28. Som, K.; Vernon, G.; Isaac, A.; Eric, Y.D.; Jeremy, T.O.; Tignegre, J.B.; Belem, J.; Tarpaga, M.V. Diversity analysis of sweet potato (Ipomoea batatas [L.] Lam) germplasm from Burkina Faso using morphological and simple sequence repeats markers. Afr. J. Biotechnol. 2014, 13, 729-742. [CrossRef]

29. Perelli, M.; Graziano, P.L.; Calzavara, R. Nutrire le Piante; ARVAN: Venice, Italy, 2009.

30. Hu, J.; Nakatani, M.; Mizuno, K.; Fujimura, T. Development and Characterization of Microsatellite Markers in Sweetpotato. Breed. Sci. 2004, 54, 177-188. [CrossRef]

31. Schuelke, M. An economic method for the fluorescent labeling of PCR fragments. Nat. Biotechnol. 2000, 18, 233. [CrossRef] 
32. Palumbo, F.; Galla, G.; Vitulo, N.; Barcaccia, G. First draft genome sequencing of fennel (Foeniculum Vulgare Mill.): Identification of simple sequence repeats and their application in marker-assisted breeding. Mol. Breed. 2018, 38, 1-17. [CrossRef]

33. Botstein, D.; White, R.L.; Skolnick, M.; Davis, R.W. Construction of a genetic linkage map in man using restriction fragment length polymorphisms. Am. J. Hum. Genet. 1980, 32, 314-331.

34. Dice, L.R. Measures of the Amount of Ecologic Association Between Species. Ecology 1945, 26, $297-302$. [CrossRef]

35. Rohlf, F.J. NTSYS-pc: Numerical Taxonomy and Multivariate Analysis System; Applied Biostatistics Inc.: Setauket, NY, USA, 2008.

36. Hammer, Ø.; Harper, D.A.; Ryan, P.D. PAST: Paleontological Statistics Software Package for Education and Data Analysis. Palaeontol. Electron. 2001, 4, 9.

37. Peakall, R.; Smouse, P.E. GenALEx 6.5: Genetic analysis in Excel. Population genetic software for teaching and research-an update. Bioinformatics 2012, 28, 2537-2539. [CrossRef] [PubMed]

38. Falush, D.; Stephens, M.; Pritchard, J.K. Inference of population structure using multilocus genotype data: Linked loci and correlated allele frequencies. Genetics 2003, 164, 1567-1587. [PubMed]

39. Porras-Hurtado, L.; Ruiz, Y.; Santos, C.; Phillips, C.; Carracedo, Á.; Lareu, M.V. An overview of STRUCTURE: Applications, parameter settings, and supporting software. Front. Genet. 2013, 4, 1-13. [CrossRef]

40. Pritchard, J.K.; Stephens, M.; Donnelly, P. Inference of population structure using multilocus genotype data. Genetics 2000, 155, 945-959. [PubMed]

41. Evanno, G.; Regnaut, S.; Goudet, J. Detecting the number of clusters of individuals using the software STRUCTURE: A simulation study. Mol. Ecol. 2005, 14, 2611-2620. [CrossRef] [PubMed]

42. IBPGR Descriptors for Sweet Potato; Huamán, Z. (Ed.) International Board for Plant Genetic Resources: Rome, Italy, 1991.

43. Singleton, V.L.; Orthofer, R.; Lamuela-Raventós, R.M. Analysis of total phenols and other oxidation substrates and antioxidants by means of folin-ciocalteu reagent. Methods Enzymol. 1999, 299, 152-178.

44. Benzie, I.F.F.; Strain, J.J. The ferric reducing ability of plasma (FRAP) as a measure of "antioxidant power": The FRAP assay. Anal. Biochem. 1996, 239, 70-76. [CrossRef]

45. Roullier, C.; Benoit, L.; McKey, D.B.; Lebot, V. Historical collections reveal patterns of diffusion of sweet potato in Oceania obscured by modern plant movements and recombination. Proc. Natl. Acad. Sci. USA 2013, 110, 2205-2210. [CrossRef]

46. Nicolle, C.; Simon, G.; Rock, E.; Amouroux, P.; Rémésy, C. Genetic Variability Influences Carotenoid, Vitamin, Phenolic, and Mineral Content in White, Yellow, Purple, Orange, and Dark-orange Carrot Cultivars. J. Am. Soc. Hortic. Sci. 2004, 129, 523-529. [CrossRef]

47. Tsegaye, E.; Dechassa, N.; Sastry, D.E.V. Genetic Variability for Yield and other agronomic traits in sweet potato. J. Agron. 2007, 6, 94-99.

48. Solankey, S.S.; Singh, P.K.; Singh, R.K. Genetic Diversity and Interrelationship of Qualitative and Quantitative Traits in Sweet Potato. Int. J. Veg. Sci. 2015, 21, 236-248. [CrossRef]

49. Lim, S.; Xu, J.; Kim, J.; Chen, T.-Y.; Su, X.; Standard, J.; Carey, E.; Griffin, J.; Herndon, B.; Katz, B.; et al. Role of Anthocyanin-enriched Purple-fleshed Sweet Potato P40 in Colorectal Cancer Prevention. Mol. Nutr. Food Res. 2013, 57, 1908-1917. [CrossRef] [PubMed]

50. Grace, M.H.; Yousef, G.G.; Gustafson, S.J.; Truong, V.-D.; Yencho, G.C.; Lila, M.A. Phytochemical changes in phenolics, anthocyanins, ascorbic acid, and carotenoids associated with sweetpotato storage and impacts on bioactive properties. Food Chem. 2014, 145, 717-724. [CrossRef] [PubMed]

51. Lee, M.J.; Park, J.S.; Choi, D.S.; Jung, M.Y. Characterization and quantitation of anthocyanins in purple-fleshed sweet potatoes cultivated in Korea by HPLC-DAD and HPLC-ESI-QTOF-MS/MS. J. Agric. Food Chem. 2013, 61, 3148-3158. [CrossRef] [PubMed]

52. Gorusupudi, A.; Bernstein, P.S. Macular Carotenoids: Human Health Aspects. In Carotenoids: Nutrition, Analysis, and Technology; Kaczor, A., Baranska, M., Eds.; Wiley Blackwell: Pondicherry, India, 2016; pp. 59-74.

53. Park, S.Y.; Lee, S.Y.; Yang, J.W.; Lee, J.S.; Oh, S.D.; Oh, S.; Lee, S.M.; Lim, M.H.; Park, S.K.; Jang, J.S.; et al. Comparative analysis of phytochemicals and polar metabolites from colored sweet potato (Ipomoea batatas L.) tubers. Food Sci. Biotechnol. 2016, 25, 283-291. [CrossRef] 
54. Simonne, A.H.; Kays, S.J.; Koehler, P.E.; Eitenmiller, R.R. Assessment of $\beta$-Carotene content in sweetpotato breeding lines in relation to dietary requirements. J. Food Compos. Anal. 1993, 6, 336-345. [CrossRef]

55. Wei, S.; Lu, G.; Cao, H. Effects of cooking methods on starch and sugar composition of sweetpotato storage roots. PLoS ONE 2017, 12, e0182604. [CrossRef]

(C) 2019 by the authors. Licensee MDPI, Basel, Switzerland. This article is an open access article distributed under the terms and conditions of the Creative Commons Attribution (CC BY) license (http://creativecommons.org/licenses/by/4.0/). 